\title{
Reduced cervical cancer incidence and mortality in Canada: national data from 1932 to 2006
}

\author{
James A Dickinson ${ }^{1,5^{*}}$, Agata Stankiewicz ${ }^{2}$, Cathy Popadiuk ${ }^{3}$, Lisa Pogany ${ }^{2}$, Jay Onysko ${ }^{2}$ and Anthony B Miller ${ }^{4}$
}

\begin{abstract}
Background: High levels of participation in cervical screening are reported in Canada from the 1970's as a result of early uptake of the Pap smear and universal Medicare. Despite recommendations to the contrary, the programs have featured early age of initiation of screening and frequent screening intervals. Other countries have achieved successful outcomes without such features. We analyzed national data to better understand mortality and incidence trends, and their relationships to screening.

Methods: The Canadian Cancer Registry, National Cancer Incidence Reporting System, and the Canadian Vital Statistics Database were used to measure mortality and incidence rates. Cases and deaths from invasive cervical cancer were classified by 5 year age groups at diagnosis and death (15 to 19 years through to 80 to 84 years), year of diagnosis (1972 to 2006), and year of death (1932 to 2006). Probabilities of developing and dying from cervical cancer were calculated for age-specific mortality and incidence. The proportion of women reporting a timely Pap test was estimated for 1978 to 2006.
\end{abstract}

Results: Cervical cancer mortality has declined steadily from a peak of 13.5 to 2.2 per 100,000 (83\%,) between 1952 and 2006, and 71\% between 1972 and 2006. Incidence of invasive cervical cancer has declined by 58\% since 1972. These declines have occurred more among older age groups than younger. Invasive cervical cancer incidence and mortality is less in each successive birth cohort of women. Participation rates in screening are high especially in women under age 50.

Conclusions: Despite increasing risk factors for cervical cancer, both incidence and mortality have declined over time, across age groups, and across birth cohorts. Earlier increasing mortality (1932 - 1950) was likely related to improved classification of cancers and the early subsequent reduction (1950 - 1970) to improved treatment. Recent improvements in incidence and mortality are likely due to high rates of screening. For women under age 30 years there are low rates of disease but lesser improvement related to screening.

Keywords: Cervical cancer, Epidemiology, Incidence, Mortality, Trends, Screening, Canada

\section{Background}

Cervical cancer is one of the most common cancers among women worldwide: third in incidence overall [1]. In Canada, cervical cancer was frequent, but now ranks $11^{\text {th }}$ for incidence and $16^{\text {th }}$ for cancer-related mortality [1-3]. Approximately 1,300 women were diagnosed and

\footnotetext{
* Correspondence: dickinsj@ucalgary.ca

'Departments of Family Medicine and Community Health Sciences, University of Calgary, Calgary, Alberta, Canada

${ }^{5}$ Family Medicine and Primary Care Research Office, University of Calgary G012, Health Sciences Centre, 3330 Hospital Drive NW, Calgary, Alberta T2N 4N1, Canada

Full list of author information is available at the end of the article
}

about 350 women died from the disease in Canada during $2011[4,5]$.

Canada was an early adopter of cervical cancer screening from 1949 in British Columbia with gradual intensification across the country [6]. Beginning in the 1960's, intensification of screening was linked to oral contraceptive prescriptions and pre- and post-natal care resulting in high screening rates among women younger than 35 [6,7]. In the early 1970's cervical cancer screening became partially subsidized and ultimately free of charge in 1984. Thereafter, uptake of screening increased [8]. By 1973 , the screening rate was near $50 \%$, and by 1997 , over $75 \%$ among women between 18 and 64 years [7]. During

\section{Biomed Central}


this time period, annual screening was the norm, beginning at age 18 or even younger and ceasing at age $69[9,10]$. By 1976, screening was linked to a reduction in mortality from cancer of the uterus as a whole, which includes cancer of the cervix [11]. Screening was adopted without a randomized trial to demonstrate its efficacy, and there is limited data to elucidate which ages or subgroups of women should be screened [12]. The need for screening at ages younger than 25 has been questioned because of the low incidence and high rates of false positives, causing large numbers of referrals for colposcopy [13].

The understanding that nearly all cervical cancer is caused by oncogenic strains of the human papillomavirus (HPV) has assisted in better interpretation of the associations between behavior and cervical cancer. The United Kingdom has observed fluctuations of cervical cancer incidence: women who reached early adulthood in times of war had higher rates than those who matured during peace $[14,15]$. Other European countries have demonstrated changes in incidence and mortality because of period and cohort effects related to the coverage and effectiveness of screening policies [16,17].

Canada has near universal availability of cervical screening, and has had policies encouraging starting screening early in life and repeating frequently. There is also high quality long-term national data on mortality and incidence. To assess the effect of this intense screening, we used national data on mortality and incidence to analyze changes in the mortality and incidence of invasive cervical cancer over time, by age group and birth cohort, and relate this to screening activity and other factors that have affected this cancer.

\section{Methods}

\section{Data sources}

Mortality data were obtained from the Canadian Vital Statistics Database (1950 - 2006) and annual Statistics Canada publications (1932-1949) [18,19]. Incidence data were obtained from the Canadian Cancer Registry (1992 - 2006) and the National Cancer Incidence Reporting System (1972 - 1991) [4,19,20]. Multiple primary coding rules of the International Agency for Research on Cancer were utilized [21]. For incidence, cancers (C53) were classified according to the International Classification of Disease for Oncology Third Edition. For mortality, cancers (C53) were classified according to the International Statistical Classification of Diseases and Related Health Problems, Tenth Revision $[22,23]$. Deaths were included when cervical cancer was determined to be the underlying cause of death. Population estimates were obtained from Statistics Canada [18,24-42] and are based on intercensal estimates from 1932 - 2005 and post censal estimates for 2006 and 2007. Estimates from 1932 to 1970 were not adjusted for enumeration undercounts resulting in small relative drops in incidence for the years from 1971. For 1971 the ratio of the adjusted estimate to the unadjusted census population estimate for women is 1.015. Direct age standardization was performed using the Canadian 1991 population as standard.

Table 1 Reduction in age specific mortality rates from invasive cervical cancer in Canada: 1952 - 2006 and 1972 - 2006

\begin{tabular}{|c|c|c|c|c|c|c|c|c|}
\hline \multirow[t]{2}{*}{ Age Group } & \multicolumn{2}{|c|}{$1952-1956$} & \multicolumn{2}{|c|}{$1972-1976$} & \multicolumn{2}{|c|}{$2002-2006$} & \multirow{2}{*}{$\begin{array}{c}1952-2006 \\
\% \text { Mortality } \\
\text { Rate Reduction }\end{array}$} & \multirow{2}{*}{$\begin{array}{c}1972-2006 \\
\% \text { Mortality } \\
\text { Rate Reduction }\end{array}$} \\
\hline & Deaths & $\begin{array}{c}\text { Rate } \\
\text { (Per 100,000) }\end{array}$ & Deaths & $\begin{array}{c}\text { Rate } \\
\text { (Per 100,000) }\end{array}$ & Deaths & $\begin{array}{c}\text { Rate } \\
\text { (Per 100,000) }\end{array}$ & & \\
\hline 15 to 19 & 0 & 0 & * & * & 0 & 0.0 & $-^{*}$ & $-^{*}$ \\
\hline 20 to 24 & 9 & 0.3 & 5 & 0.1 & 9 & 0.2 & $-^{*}$ & $-^{*}$ \\
\hline 25 to 29 & 51 & 1.7 & 30 & 0.6 & 31 & 0.6 & $-^{*}$ & $-^{*}$ \\
\hline 30 to 34 & 137 & 4.7 & 66 & 1.8 & 65 & 1.2 & 75 & 32 \\
\hline 35 to 39 & 223 & 8.3 & 121 & 3.8 & 105 & 1.7 & 79 & 54 \\
\hline 40 to 44 & 337 & 14.3 & 167 & 5.3 & 172 & 2.5 & 82 & 52 \\
\hline 45 to 49 & 417 & 21.0 & 280 & 8.9 & 197 & 3.1 & 85 & 66 \\
\hline 50 to 54 & 357 & 21.0 & 303 & 10.1 & 223 & 3.9 & 81 & 61 \\
\hline 55 to 59 & 325 & 21.9 & 326 & 12.9 & 186 & 3.8 & 82 & 70 \\
\hline 60 to 64 & 357 & 28.2 & 319 & 14.3 & 145 & 3.9 & 86 & 73 \\
\hline 65 to 69 & 311 & 28.5 & 281 & 15.6 & 141 & 4.6 & 84 & 70 \\
\hline 70 to 74 & 238 & 27.7 & 244 & 17.6 & 149 & 5.4 & 81 & 70 \\
\hline 75 to 79 & 176 & 32.9 & 234 & 23.2 & 145 & 6.0 & 82 & 74 \\
\hline 80 to 84 & 81 & 28.3 & 135 & 20.9 & 155 & 8.3 & 71 & 60 \\
\hline
\end{tabular}

*Deaths, mortality rate and mortality reduction is not provided due to small numbers of cases and the resulting susceptibility to spurious variation. 


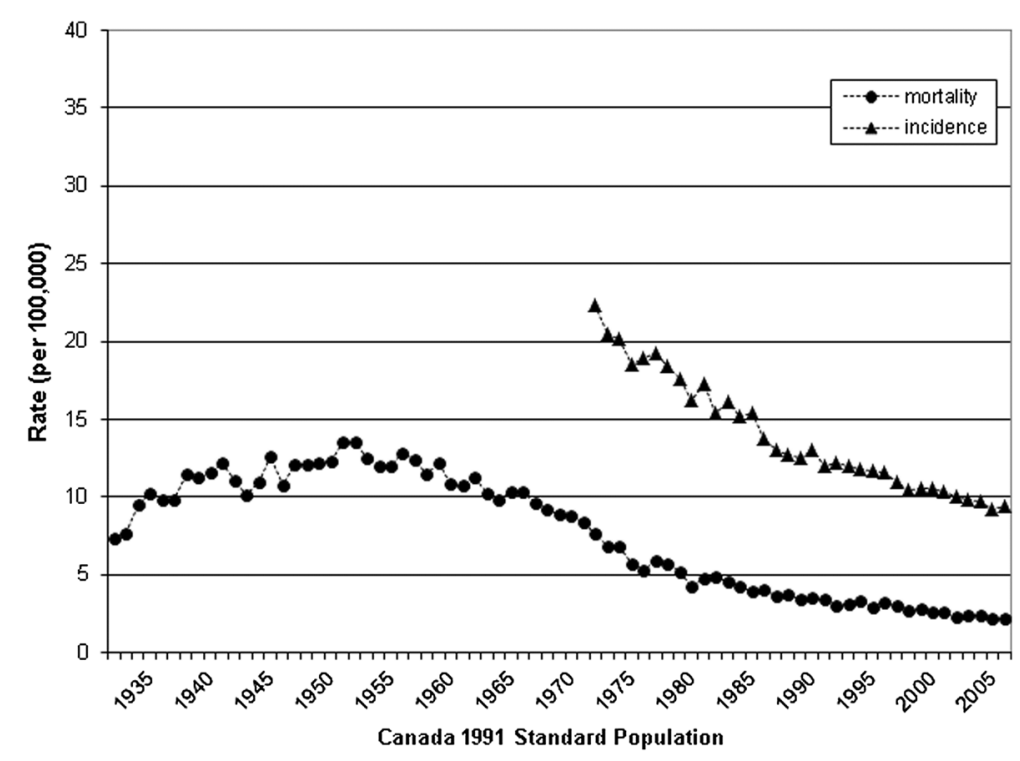

Figure 1 Age standardized mortality and incidence of cervical cancer in Canada.

Ethical approval was not required, since routinely collected de-identified data were analysed within the confidential environment of the Public Health Agency of Canada by their staff (JO, AS, LP), and only aggregate data were released, following standard rules for suppression of cells containing very small numbers.

\section{Analysis}

Data were classified by 5 year age groups at diagnosis and death (15 to 19 years through to 80 to 84 years), year of diagnosis (1972 to 2006) and year of death (1932 to 2006). The 80 to 84 age group was chosen as the cut-off because it was the eldest available 5-year age group. Incidence and mortality rates for each category were calculated by dividing the number of cases or deaths in each category by the census population. Percent reductions among 5-year age groups were calculated using five-year period mortality and incidence rates. Denominators were not adjusted for hysterectomy. Rates based on 1 to 5 observations for incidence and 1 to

Table 2 Reduction in age specific incidence rates from invasive cervical cancer in Canada: 1952 - 2006 and 1972 - 2006

\begin{tabular}{|c|c|c|c|c|c|}
\hline \multirow[t]{2}{*}{ Age Group } & \multicolumn{2}{|c|}{$1972-1976$} & \multicolumn{2}{|c|}{$2002-2006$} & \multirow{2}{*}{$\begin{array}{c}\% \text { Incidence } \\
\text { Rate Reduction }\end{array}$} \\
\hline & New Cases & $\begin{array}{c}\text { Rate (per } 100,000) \\
1972 \text { to } 1976\end{array}$ & New Cases & $\begin{array}{l}\text { Rate (per } 100,000) \\
2002 \text { to } 2006\end{array}$ & \\
\hline 15 to 19 & 15 & 0.3 & 9 & 0.2 & 35 \\
\hline 20 to 24 & 143 & 2.7 & 70 & 1.3 & 52 \\
\hline 25 to 29 & 429 & 9.1 & 355 & 6.7 & 26 \\
\hline 30 to 34 & 643 & 17.1 & 689 & 12.7 & 26 \\
\hline 35 to 39 & 660 & 20.7 & 794 & 13.2 & 36 \\
\hline 40 to 44 & 787 & 25.0 & 982 & 14.5 & 42 \\
\hline 45 to 49 & 924 & 29.4 & 821 & 12.8 & 57 \\
\hline 50 to 54 & 919 & 30.6 & 694 & 12.2 & 60 \\
\hline 55 to 59 & 822 & 32.5 & 532 & 10.9 & 66 \\
\hline 60 to 64 & 752 & 33.8 & 404 & 10.8 & 68 \\
\hline 65 to 69 & 629 & 34.9 & 329 & 10.8 & 69 \\
\hline 70 to 74 & 456 & 32.9 & 279 & 10.0 & 69 \\
\hline 75 to 79 & 314 & 31.1 & 288 & 11.9 & 62 \\
\hline 80 to 84 & 182 & 28.2 & 246 & 13.2 & 53 \\
\hline
\end{tabular}




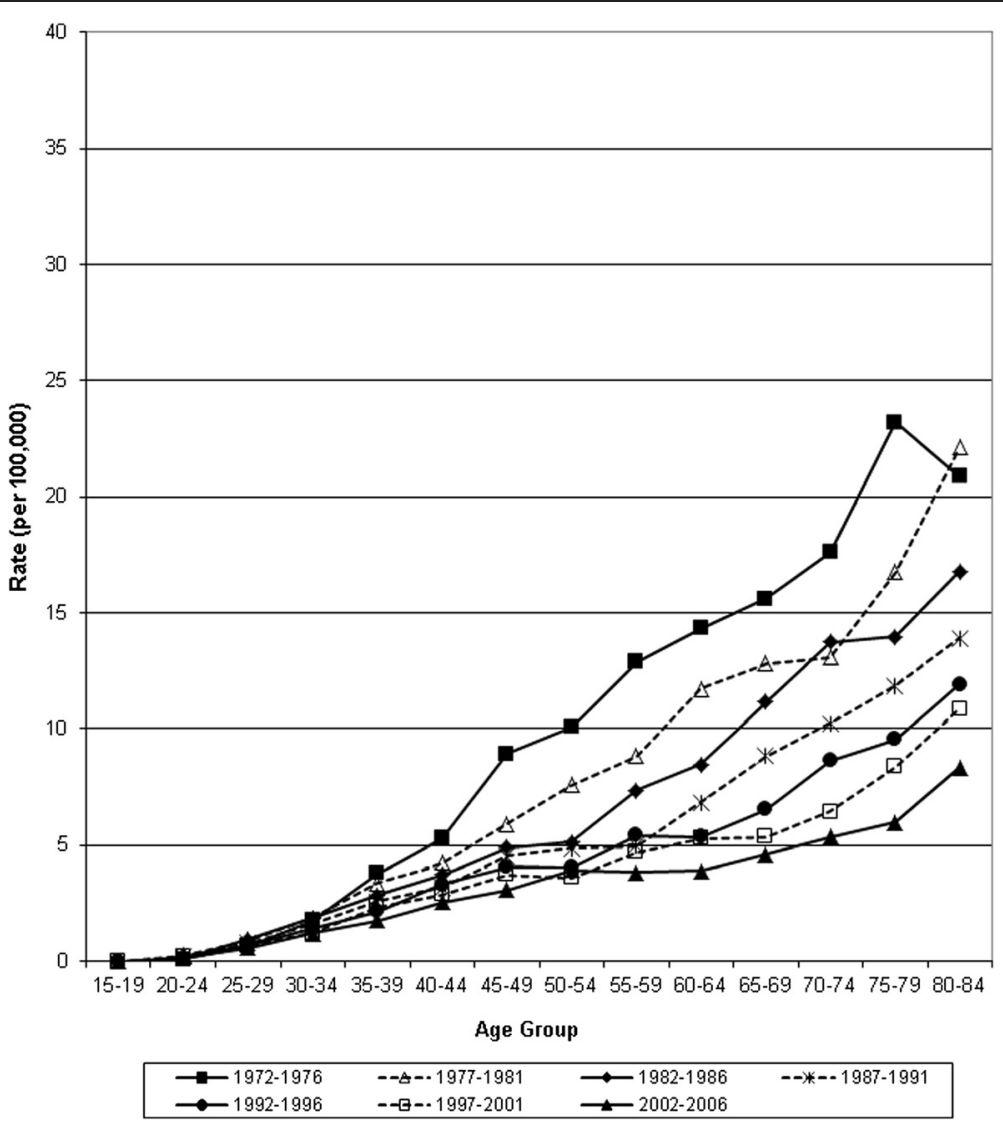

Figure 2 Age-specific mortality from invasive cervical cancer in Canada, 1972-2006.

4 observations for mortality were suppressed for confidentiality purposes

Probabilities of developing and dying from cervical cancer were calculated for age-specific mortality (1952, 1972 and 2006) and incidence (1972 and 2006). Respective life tables were based on 1951 to 1953, 1971 to 1973 and 2005 to 2007 all-cause mortality rates. Calculation of the probability of developing and dying from cancer were based on standard methods $[43,44]$.

Data used to estimate the proportion of women with a timely Pap test uptake were obtained from the Canada Health Survey 1978-1979, Health Promotion Survey 1985, 1990, National Population Health Survey 19941995, 1996-1997, 1998-1999, and Canadian Community Health Survey cycles 1.1 (2001), 2.1 (2003), 3.1 (2005), and Canadian Community Health Survey - Annual Component, 2008. Timely cervical cancer screening was defined as having had a pap smear test within 3 years for all surveys except the CHS 1978-79 which used a two year period. Denominators for these survey reports were adjusted for hysterectomy from 1996-1997 onwards. Detailed information on the above survey designs, sample sizes and methodologies is available upon request.

\section{Results}

\section{Overall}

Age standardized mortality from invasive cervical cancer declined 83\% from 1952 to 2006 (13.2 to 2.2 per 100,000 women respectively). About half of the decline occurred between 1972 and 2006 (7.7 to 2.2 per 100,000 women respectively) (Table $1 \&$ Figure 1$)$. Age-standardized incidence declined 58\% between 1972 (22.3 per 100,000) and 2006 (9.4 per 100,000) (Figure 1 \& Table 2). This was notable over the age of 40 , with lesser effects below that age, except for a relative reduction of $50 \%$ for women aged 20-24. Figures 2 and 3 show a steady sequential reduction of age-specific mortality and incidence from 1972 to 2006. The greatest declines in both mortality and incidence are observed in age groups over 45 years with reductions as high as $74 \%$ in mortality and $69 \%$ in incidence (Tables $1 \& 2$ ).

\section{Trends by calendar year}

After initial rises in mortality for older women, there was a steady decline among women younger than 60 years from the 1940s, and among women over 


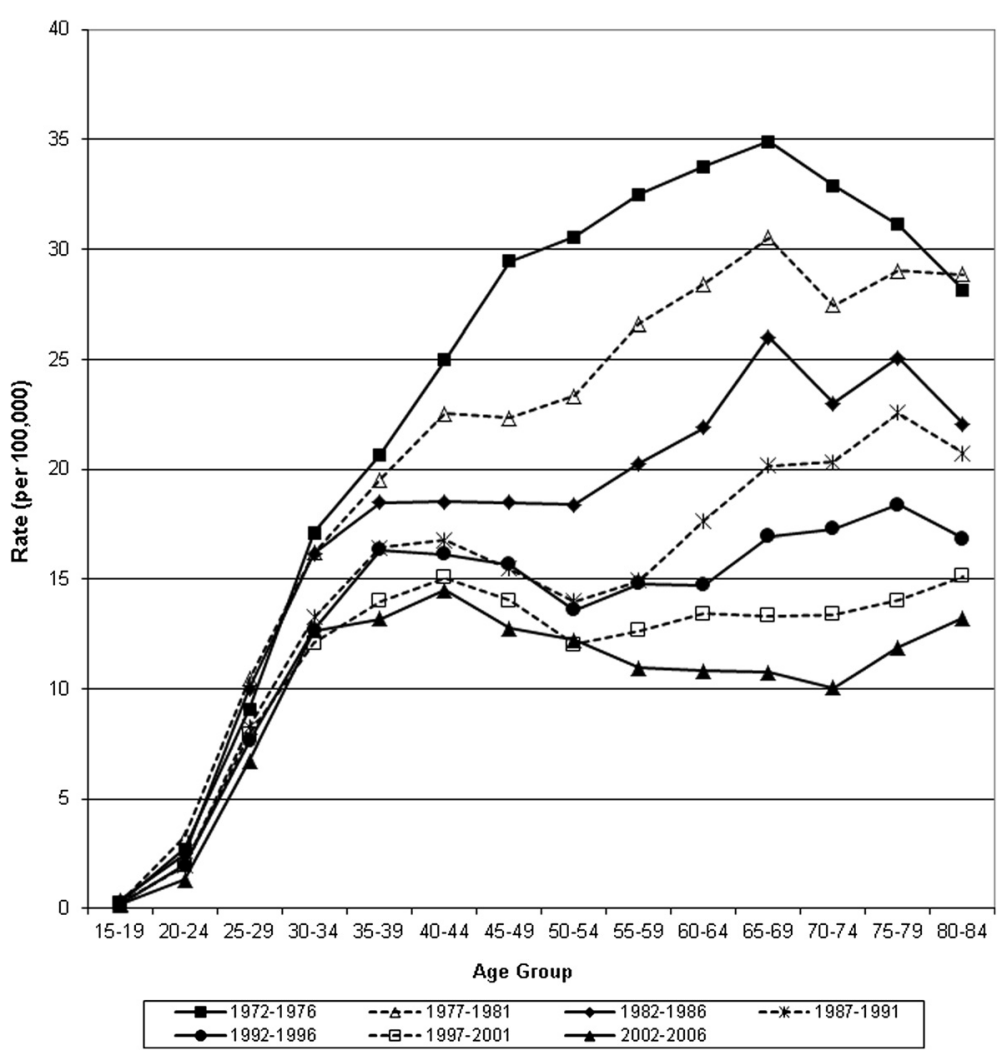

Figure 3 Age-specific incidence of invasive cervical cancer for 5 year periods, 1972-2006.

60 years of age from the 1950 - 1960s (Figure 4). Incidence declined for all age groups from 1972 to 2006, most apparent in women above age 30 and the reduction was larger at ages over 45 years (Figure 5 ).

\section{Trends by birth cohort}

Age-specific mortality and incidence were compared by birth cohorts for women born between 1890 and 1989 (Figures $6 \&$ 7). A steady progression to lower mortality from the earliest to the most recent birth cohorts is observed with peak mortality dropping from 28.2 deaths to 4.1 deaths per 100,000 women. Peak mortality rates occurred at progressively younger ages from the 189094 cohort to 1930-34 cohort. The most recent birth cohorts (1940 to 1989), have lower initial increases in mortality but rates continue to rise with age and it is not possible to discern whether they will drop after the $4^{\text {th }}$ decade. Women among the earliest birth cohorts experienced twice the peak incidence of invasive cervical cancer than women in the birth cohorts after 1950 (Figure 7). In 1952, the lifetime probability of death from cervical cancer (percent) was 0.94 , by 1972 it was 0.66 , and by 2006, 0.22 . The lifetime probability of developing invasive cervical cancer fell from 1.54 to 0.66 (1972 and 2006 respectively).

\section{Uptake of screening}

Canada-wide community health surveys show consistent rates of cervical screening between 1978 and 2006: over $40 \%$ among $18-19$ year-olds, rising to mostly over $80 \%$ during the young adult ages, then dropping thereafter, especially after age 70 (Table 3). The rates are lower in the 1978-9 survey, largely accounted for by the two-year definition of timely uptake.

\section{Discussion}

Incidence and mortality from invasive cervical cancer has declined in Canada since the 1950s. For most age groups mortality has declined by over $80 \%$ since the 1950 s and $50 \%$ since the 1970 s respectively (Table 1) while incidence declined by more than $50 \%$ since the 1970s (Table 2). Mortality reductions are small for women under the age of 30 and greater for older women, with the largest reductions over the age of 50 years. Period analysis suggests rising mortality for older age groups until the 1950s and 1960s, then steady reductions for all age groups from the 1970s. Birth cohort analysis demonstrates differing trajectories between the most recent and distant cohorts: among recent cohorts small increases in mortality rates with age peak at approximately 4 deaths per 100,000 women, compared to over 24 deaths per 100,000 women among those born 


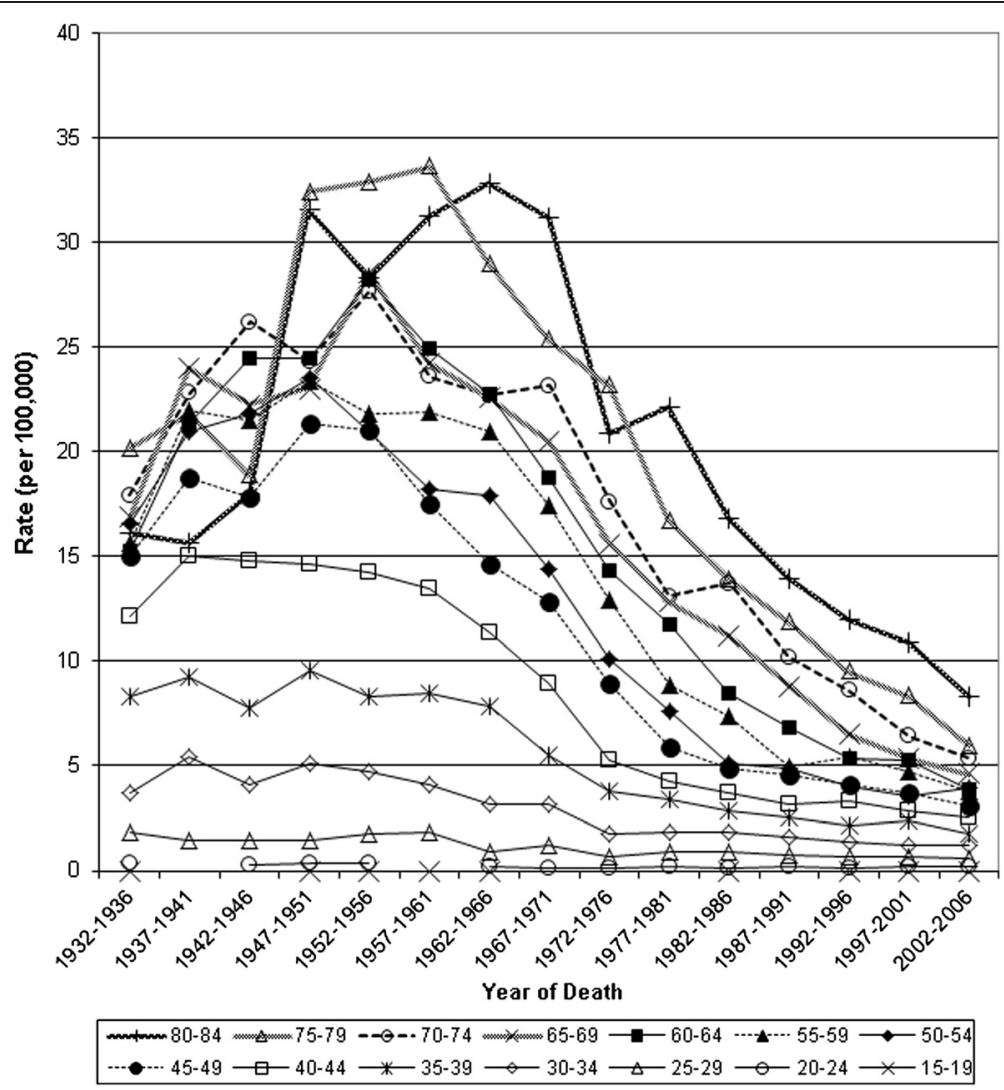

Figure 4 Mortality from invasive cervical cancer in Canada, 1932-2006: trends by year of death.

before 1900. Cohort analysis of incidence demonstrates steady reductions for all age groups, especially over age 40, and extrapolating backwards suggests that Canada previously had a substantially higher incidence.

Reductions in both mortality and incidence are influenced by changes in the quality of death certification and disease registration, improvement in diagnosis and treatment, and screening for early disease. The increases in mortality before 1950 are likely due to classification errors (see data limitations). Subsequent reductions were initially probably related to introduction of effective treatment. In the post-World War II era of 1950 to 1970, the specialty of gynecology developed rapidly, initial treatment of cancer was done by well-trained gynecological surgeons, and radiotherapy became readily available across the country. Gynecological oncology as a specialty became widely available in the 1970s and 80s. These developments led to improved diagnosis and treatment, and likely contributed to the trends seen in mortality before 1975. Analysis of data from the Karolinska hospital in Sweden, together with trends in mortality from cancer of the cervix in that country, suggested that the introduction of radiotherapy for cancer of the cervix led to an important reduction in cervix cancer mortality [45]. Treatment techniques have only changed incrementally since then with addition of more effective chemotherapy [46], so are likely to have made smaller differences to mortality from about 1980, but mortality from cervical cancer in Canada continues to decline substantially. There was an apparent spike in incidence between about 1972 and 1980, most evident for women in the youngest age groups. This is clear in the data from British Columbia, a province that has a longer data series (Figure 8). Pathologists active at the time ascribed this to artefact due to the introduction of colposcopy, leading to more frequent use of punch biopsies that were difficult to assess, and produced more "over-diagnosis" of lesions that would regress. (personal communication D van Niekerk). This likely occurred across the country and exaggerated the apparent reductions in incidence based on national data from 19721976, especially at younger ages, where this artefact is greater in proportion to the total.

Screening rates in Canada have been consistently high from early ages and persisting until age 70 , especially notable after 1996-7 when hysterectomy corrections were applied to the analyses (Table 3 [47] These high proportions are not adjusted for sexual activity but screening has been associated with the practice of prescribing contraception and pre and post-natal care, 


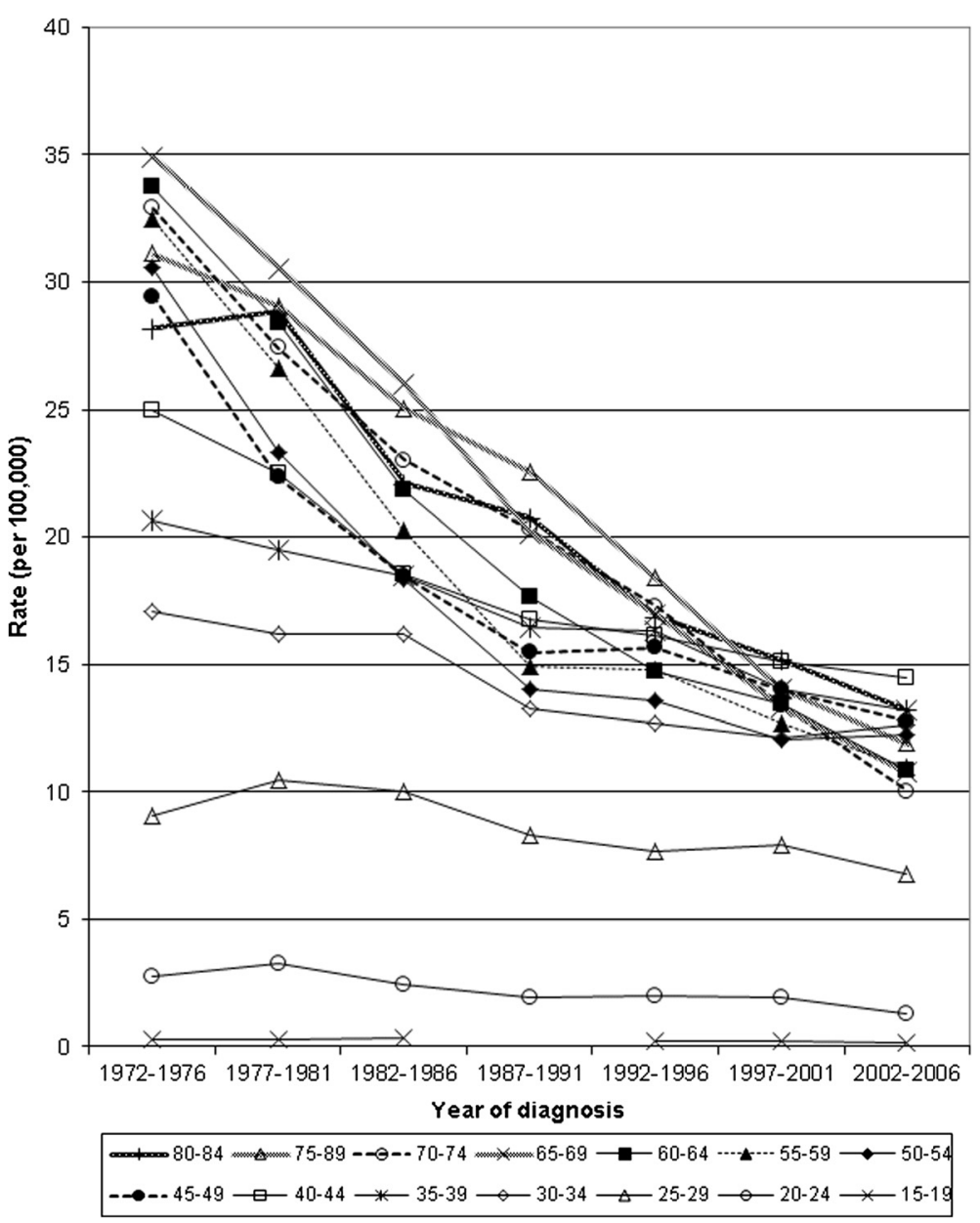

Figure 5 Incidence of invasive cervical cancer in Canada, 1972-2006: trends by year of diagnosis.

therefore it is likely that most sexually active women are screened. This has occurred despite most screening being opportunistic: programs of systematic populationbased reminders and recall have only commenced in recent years in some provinces [47]. Recent immigrants, those with lower incomes and rural women are less likely to have regular screening $[48,49]$, so there is scope for improvement, as has been shown for aboriginal women [50].

A further factor that could affect both incidence and mortality of cervical cancer is change in the underlying epidemiology of infection and carcinogenesis by HPV. This could be influenced by behavior change or by immigration from countries with high cervical cancer rates. Relevant behaviour change may include early commencement of sexual activity, increased number of partners (not only of women, but of their consorts), smoking, and oral contraceptive use [12]. These might be expected to increase incidence rates, especially from the late 1960s when oral contraceptive use became widespread, and women in the cohorts born between 1930 and 1950 steadily increased smoking behaviour. Further, Canada has experienced substantial immigration since the 1950s, initially from Europe, then from various Asian countries, South America and Africa. Many of these areas have high cervical cancer rates [1], but immigrant women are less likely to be screened [48,49], so immigration may have attenuated the decrease in incidence and mortality that is observed.

Cervical screening is effective largely because it increases detection of pre-cancer (CIN, Ca-in-situ), and treatment prevents progression to invasive cancer [16]. Therefore the observed reductions in incidence are most likely due to screening, especially since risk factors have increased. If cancer still develops in a screened population, it is usually detected at an earlier stage and is therefore more amenable to curative treatment, so the program reduces mortality by two mechanisms. Some effect of screening began from 1949, in parallel with improved treatments, and in the 1960s when screening 


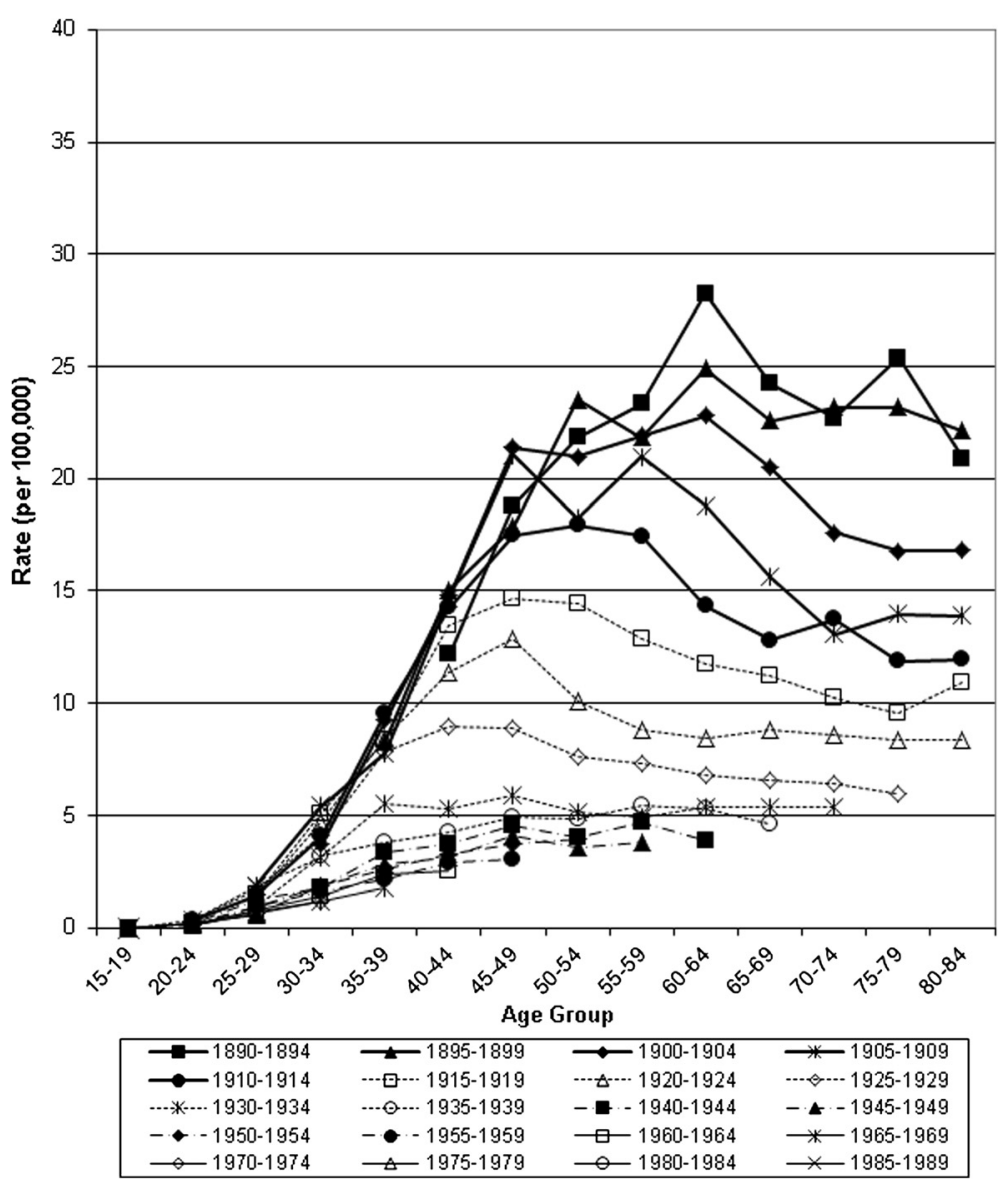

Figure 6 Mortality from invasive cervical cancer in Canada, 1932-2006: trends by year of birth.

became widespread, mortality dropped further and was clearly related to screening [11]. Since then it has dropped yet more, despite minimal advances in treatment and the increased risk factors noted, so the continuing reduction can be ascribed to screening. From the 1990s, the rate of decrease has flattened out: which may be partly due to greater difficulty in reaching some segments of the population, and partly from reaching the limit of what can be achieved with screening. Adenocarcinoma of the cervix is less amenable to cytological screening, and while this used to comprise a small fraction, as squamous carcinomas are removed, they become a larger fraction [51,52]. In addition, more rapidly growing cancers are difficult to detect by screening and to treat [16].

Countries that have not instituted widespread screening have observed little change in cervical cancer mortality or incidence [53]. Substantial drops in incidence and mortality from cervical cancer in Canada have followed a different pattern from those found in the United Kingdom (UK) and some other European countries over the same period [17]. Canada showed a substantial reduction of incidence about a decade before the UK, where gynecological oncology treatment was also well developed but a major program of organized cervical screening was not introduced until 1988 [16]. The United Kingdom has observed fluctuations of cervical cancer incidence that relate to behaviours: women who reached early adulthood in times of war had higher rates than those before and after [14,15]. By contrast, Canada experienced no increase that can be ascribed to infection during the war years, nor after the introduction of oral contraception in the late 1960s.

The effect of screening is age dependent: mortality changes in the age groups under 25 are too small to assess in this analysis, and for those aged 25-29, most of the reduction occurred before 1972, so may have been as much due to treatment as screening. The greatest reductions both in proportion and numbers occur in mature women, about half before 1972-6. Thus it is likely that treatment reduced mortality, but screening added to this effect. Since it became widespread, screening has probably reduced the need for treatment of advanced disease, but at the cost of treating minor 


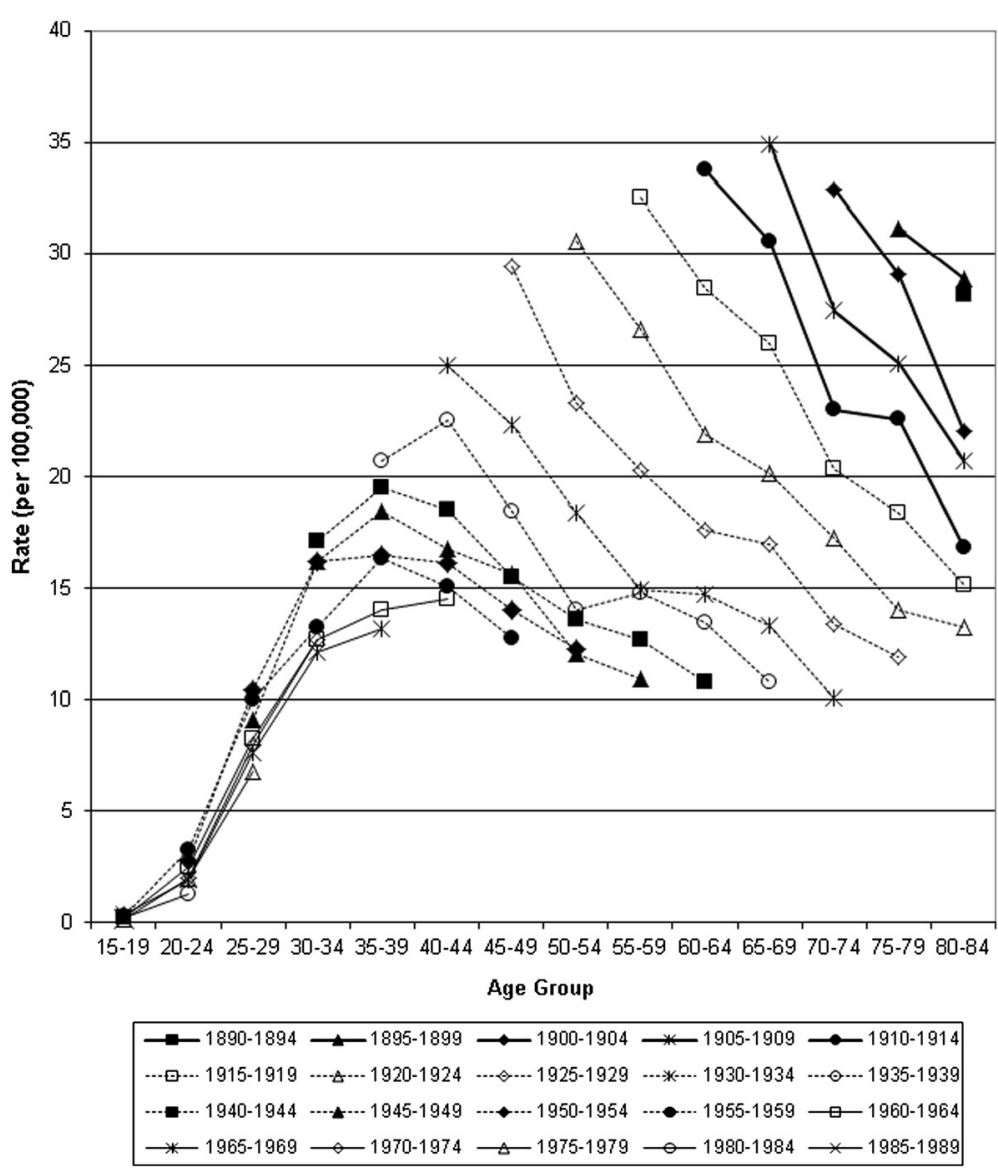

Figure 7 Incidence of invasive cervical cancer in Canada, 1972-2006: trends by year of birth.

changes that are diagnosed as possible malignant precursors, causing artefactual increases in incidence especially among young women at the time that colposcopy was introduced. This artefact makes it difficult to accurately quantify the effect of screening on incidence among the lowest age groups. A limited effect of screening on reducing incidence under the age of 30 was found in a UK case control study [54].

The reduction in mortality from cervical cancer has been very similar in Canada, the United States and Finland [16]. Finland has an organized program, with screening every 5 years, largely restricted to women age 30-59. Programs of annual screening in North America over a much wider age range than Finland have placed a greater burden on women, causing more harm in terms of follow-up and over-treatment of early disease, and used far more medical resources, especially among women under age 30 years [13]. An IARC working group has recommended that screening should not start in any country before the age of 25 [12]. As the era of HPV testing arrives, policies must be planned to obtain a better balance of benefit, effort and harm, across all ages.

\section{Limitations of the data}

This analysis was limited by four issues: misclassification prior to 1950, adjustment for hysterectomy, small numbers of cases among young women, and data availability. Firstly, although there have been no substantial changes in classification of cervical cancer in the ICD codes, prior to the 1970s there was misclassification of advanced disease between cervical and uterine cancer [6]. Consequently, early mortality data is likely to underestimate cervical cancer deaths. Much of the apparent rise in mortality prior to 1950 is probably due to improved classification. Secondly, incidence and mortality rates were not adjusted for hysterectomy and are therefore underestimated. This is particularly relevant for estimates among women over 45 years of age, when most hysterectomies occur. In Canada the hysterectomy rate peaked in approximately 1972, and prevalence was as high as $30 \%$ for women over 55 years [55]. However, there is insufficient hysterectomy data for us to accurately estimate hysterectomy-corrected rates by age over the whole period. An analysis on data to 1976 suggested that changing hysterectomy rates did not affect the fall in cervical cancer due to screening [56]. Since then, 
Table 3 Self-reported timely* uptake of Pap test among women aged 18 to 84 years, Canada: $1978 / 9$ to 2008

\begin{tabular}{|c|c|c|c|c|c|c|c|c|c|c|}
\hline Age Group & $\begin{array}{l}978 / 1979 \\
(95 \% \mathrm{Cl})\end{array}$ & $\begin{array}{c}1985 \\
\%(95 \% \mathrm{Cl})\end{array}$ & $\begin{array}{c}1990 \\
\%(95 \% \mathrm{Cl})\end{array}$ & $\begin{array}{l}1994 / 1995 \\
\%(95 \% \mathrm{Cl})\end{array}$ & $\begin{array}{c}1996 / 1997^{* *} \\
\%(95 \% \mathrm{Cl})\end{array}$ & $\begin{array}{c}\text { 1998/1999** } \\
\%(95 \% \mathrm{Cl})\end{array}$ & $\begin{array}{c}2001 * * \\
\%(95 \% \mathrm{Cl})\end{array}$ & $\begin{array}{c}2003 * * \\
\%(95 \% \mathrm{Cl})\end{array}$ & $\begin{array}{c}2005^{* *} \\
\%(95 \% \mathrm{Cl})\end{array}$ & $\begin{array}{c}2008 * * \\
\%(95 \% \mathrm{Cl})\end{array}$ \\
\hline 19 & $43.2(35.6-51.2)$ & $9.3(41.6-57.0)$ & $4.2(43.4-65.1)$ & $48.5(40.2-56.8)$ & $49.6(43.0-56.1)$ & $44.0(33.5-54.5)$ & $43.8(40.8-46.7)$ & $47.3(44.0-50.6)$ & $42.4(39.1-45.6)$ & $39.8(35.0-44.7)$ \\
\hline $20-24$ & $77.3(74.1-80.2)$ & $.4(80.8-86.1)$ & $.4(70.1-80.6)$ & $1(65.2-77.0)$ & $.8(68.6-77.0)$ & $3-77.7)$ & $(63.7-68.1)$ & $7.7-73.1)$ & (.6- 72.3$)$ & 77.3) \\
\hline-29 & 4) & 3) & 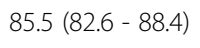 & ) & ) & 3) & 2) & 8 & 2) & 1) \\
\hline 4 & 83.7) & 8) & ) & ) & ) & 4) & 4) & 84 & 36.4) & 6) \\
\hline $35-39$ & $74.3(70.1-78.1)$ & $83.6(80.6$ - 86.6) & $82.5(76.7-88.3)$ & $80.9(76.8-85.0)$ & $84.5(82.1-86.8)$ & 85.7 (82.5 - 88.9) & $80.5(78.8-82.2)$ & $82.2(80.5-84.0)$ & $82.0(80.3-83.6)$ & $83.2(80.6-85.7)$ \\
\hline $40-44$ & $67.8(63.0-72.2)$ & $83.5(80.5-86.5)$ & $81.3(75.6-87.0)$ & $79.2(74.6-83.0)$ & $81.5(78.4-84.6)$ & $82.9(78.7-87.2)$ & $80.3(78.8-81.7)$ & $82.8(81.0-84.6)$ & $81.2(79.5-82.8)$ & $81.9(78.8$ - 84.9) \\
\hline-4 & 75.1) & $9-85.5)$ & ) & 4 & 7 & 6) & 7 & ) & 78 & 1) \\
\hline $50-54$ & 70.4) & 30.6) & 2.0) & 13.3 & $-83.7)$ & 85.2 & 79.8 & .5) & 1.6) & 77.4 \\
\hline $55-59$ & $57.3(51.3-63.1)$ & $69.0(62.7-75.4)$ & $69.3(62.8-75.8)$ & $62.3(55.5-69.1)$ & $72.5(68.1-77.0)$ & $80.5(74.9-86.1)$ & $77.4(74.9-79.8)$ & $81.9(80.3-83.5)$ & $77.6(75.8$ - 79.4) & $76.9(73.3-80.5)$ \\
\hline 64 & $42.1(36.1-48.3)$ & $9.7(64.1-75.2)$ & $65.1(58.5-71.8)$ & $60.9(54.1-67.7)$ & $64.8(59.8-69.8)$ & $74.1(67.5-80.7)$ & $72.8(69.6-76.1)$ & $74.7(72.6-76.8)$ & - 76.9) & $71.5(67.9-75.1)$ \\
\hline נטרני & $41.3(35.6-47.1)$ & $59.8(52.1-67.4)$ & $55.1(47.3-62.9)$ & $56.4(50.4-62.4)$ & $55.9(50.4-61.4)$ & $61.8(54.5-69.1)$ & $64.8(61.8-67.8)$ & $65.0(62.6-67.4)$ & $63.0(60.5-65.4)$ & $66.8(62.9-70.8)$ \\
\hline 70-74 & $28.3(21.8-35.8)$ & $50.8(42.9-58.8)$ & $41.1(32.0-50.1)$ & $35.7(29.9-41.5)$ & $46.1(41.3-50.8)$ & $55.4(46.8-64.0)$ & $50.8(47.6-54.0)$ & $54.0(51.4-56.6)$ & $51.6(49.3-53.9)$ & $48.7(43.8-53.5)$ \\
\hline 75-79 & $19.6(14.1-26.6)$ & $43.5(33.0-54.0)$ & $33.0(23.6-42.5)$ & $31.3(25.2-37.4)$ & $33.7(28.0-39.5)$ & $40.2(31.1-49.3)$ & $37.7(34.4-41.1)$ & $38.1(35.1-41.1)$ & $35.7(32.9-38.4)$ & $27.6(22.7-32.4)$ \\
\hline דים & $15.2(9.4-23.5)$ & $3.4(30.9-55.9)$ & $35.0(21.8-48.2)$ & $27.6(18.4-36.8)$ & $26.1(21.0-31.2)$ & $26.9(16.4-37.3)$ & $23.9(20.8-27.1)$ & $23.7(21.0-26.5)$ & $23.3(20.5-26.0)$ & $21.4(17.2-25.7)$ \\
\hline
\end{tabular}

Timely uptake is defined as within the last 2 years (1978/79) or within the last 3 years $(1985-2008)$.

** Hysterectomy corrections made from 1996-7 onwards. 


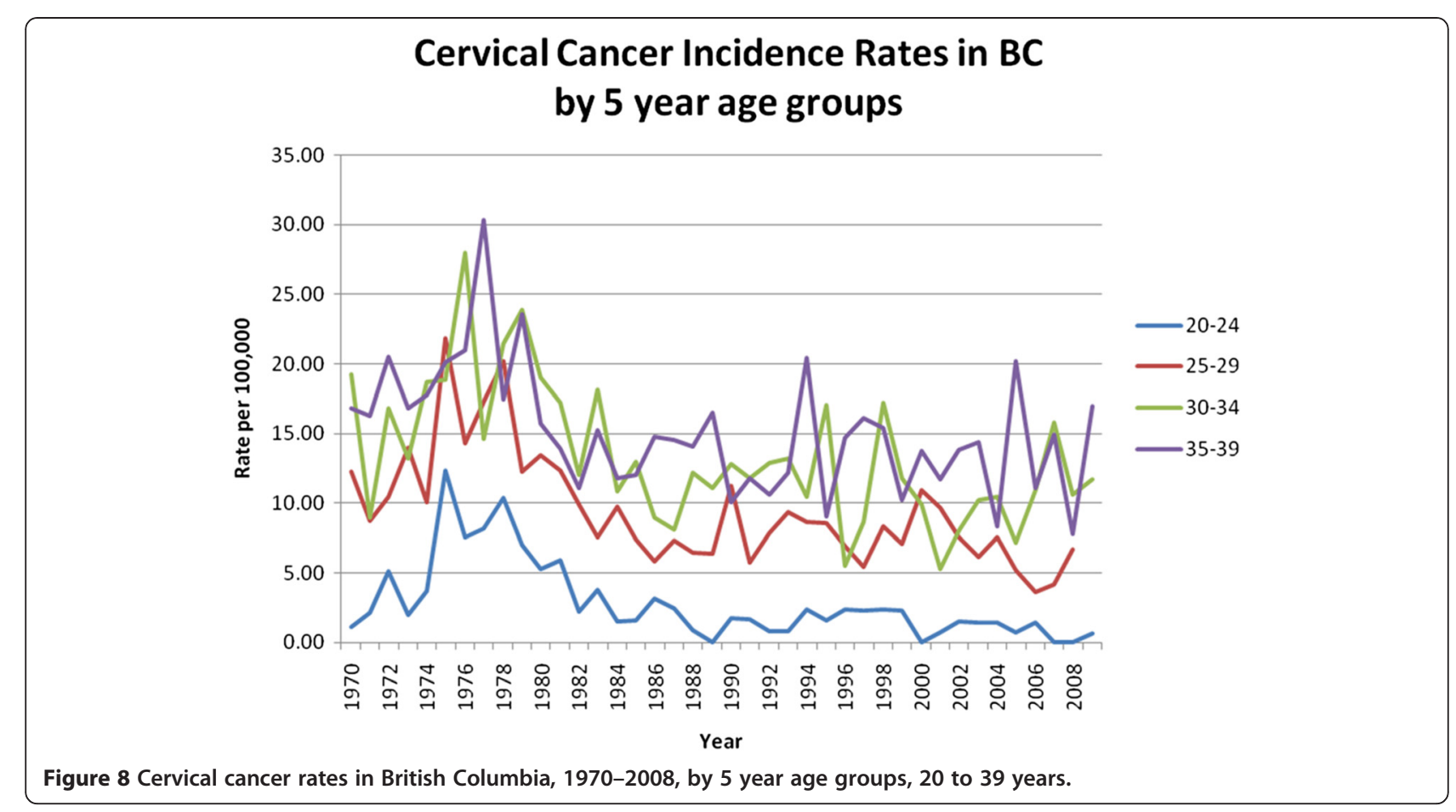

declining hysterectomy rates may have increased the denominator of women with an intact uterus and masked some of the subsequent effect of cervical screening. Thirdly, small numbers of cases and deaths in the youngest age groups make the rates susceptible to spurious variation related to small changes: including the effect that we identified of introducing colposcopy in the 1970 s, affecting especially women under 30 years. Lastly, it is desirable to analyze the incidence and mortality reductions in relation to variations in provincial screening policies, availability and uptake of screening, and changes in treatment. Sufficient data is not available to enable this, and differences between provinces are relatively small in recent years [47].

\section{Conclusions}

In Canada, high mortality from cervical cancer in the 1950s has changed to rates that are among the lowest in the world. The lifetime risk of being diagnosed with cervical cancer has fallen from $1.5 \%$ to $0.66 \%$ and the risk of dying has fallen from $0.92 \%$ to $0.22 \%$. These effects are remarkable, given that about $20 \%$ of women do not get smears, or have them infrequently [47]. Many of the invasive cancers occur among these women, who ultimately may present with late stage disease. Thus the protective effect for those who have regular cervical smears is high. Despite more sporadic screening, most of the disease reduction has occurred among women over 40 years. Although initial improvements in mortality were likely related to improved treatment more recent improvements are probably largely attributable to the effect of screening, which likely has also reduced the need for more aggressive treatment.

Among women below the age of 30 years, cervical cancer rates have always been low, and have changed little, so it will be difficult to discern any effect of HPV immunization until the immunized cohort reaches beyond the age of 30 . The approach to cervical screening policy may need to change in order to obtain the full benefit possible. Rather than starting screening at young ages and frequent re-screening of those who already participate, further advances are likely to arise from focusing on the sub-groups of the population that still have low screening rates.

\section{Competing interests}

The authors declare that they have no competing interests.

\section{Authors' contributions}

The paper topic was originated by JD, with assistance from JO and CP in developing the questions and analysis outline. Data analysis was conducted by $A S$ and LP. The paper outline was written by JD, whereas CP, LP, AS, AM and JO edited the paper. The final paper version was approved by all authors.

\section{Acknowledgements}

With acknowledgement to Robert Semenciw ${ }^{2}$ for statistical assistance. We thank Dirk van Niekerk and Lisa Kan of BC Cancer Agency for their data analysis in Figure 8.

The data contained in these figures and table were provided to the Public Health Agency of Canada from the Canadian Cancer Registry database at Statistics Canada with the knowledge and consent of the provincial and territorial cancer registries which supply the data to Statistics Canada. Their cooperation is gratefully acknowledged. 
Authors were supported by their institutions. No external source of funding contributed to this work. The data analyses were approved by Public Health Agency of Canada.

\section{Author details}

'Departments of Family Medicine and Community Health Sciences, University of Calgary, Calgary, Alberta, Canada. ${ }^{2}$ Public Health Agency of Canada, Ottawa, Ontario, Canada. ${ }^{3}$ Department of Women's Health, Memorial University, St John's, Newfoundland, Canada. ${ }^{4}$ Dalla Lana School of Public Health, University of Toronto, Toronto, Ontario, Canada. ${ }^{5}$ Family Medicine and Primary Care Research Office, University of Calgary G012, Health Sciences Centre, 3330 Hospital Drive NW, Calgary, Alberta T2N 4N1, Canada.

Received: 19 April 2012 Accepted: 12 November 2012

Published: 16 November 2012

\section{References}

1. Globocan cancer fact sheet. [cited October 11, 2011]. http://globocan.iarc.fr/ factsheets/cancers/cervix.asp.

2. Franco EL, Duarte-Franco E, Ferenczy A: Cervical cancer: Epidemiology, prevention and the role of human papillomavirus infection. CMAJ 2001, 164(7):1017.

3. Cervical cancer screening programs. I. epidemiology and natural history of carcinoma of the cervix. CMAJ 1976, 114(11):1003-1012.

4. Gaudette L, Lee J: Cancer incidence in Canada 1969-1993. Ottawa, Ontario: Ministry of Industry; 1997. Report No. 82-566-XPB.

5. Causes of death. [cited 10/17/201 1]. http://www.statcan.gc.ca/pub/84-208-x/ 84-208-x2010001-eng.htm.

6. Walton J, (chairman) Task force on Cervical Cancer Screening: Cervical cancer screening programs. II. Screening for carcinoma of the cervix. CMAJ 1976, 114(11):1013-1026.

7. Maxwell CJ, Bancej CM, Snider J, Vik SA: Factors important in promoting cervical cancer screening among Canadian women: Findings from the 1996-97 national population health survey (NPHS). Can J Public Health 2001, 92(2):127.

8. Ng E, Wilkins R, Fung MF, Berthelot JM: Cervical cancer mortality by neighbourhood income in urban Canada from 1971 to 1996. CMAJ 2004, 170(10):1545-1549.

9. Cervical cancer screening programs: Summary of the 1982 Canadian Task Force report. CMAJ 1982, 127(7):581-589.

10. Stuart GC, O'Connell G, Ferenczy A: Screening for cancer of the cervix. CMAJ 1991, 145(10):1195.

11. Miller $A B$, Lindsay J, Hill GB: Mortality from cancer of the uterus in Canada and its relationship to screening for cancer of the cervix. Int J Cancer 1976, 17(5):602-612.

12. International Agency for Research on Cancer: Cervix Cancer Screening. IARC Handbooks of Cancer Prevention, Vol. 10. Lyon: IARC Press; 2005.

13. Alberta Cervical Cancer Screening Program Committee: Guideline for screening for cervical cancer. Revised, 2009. Edmonton: Towards Optimized Practice Program; 2009

14. Beral V: Cancer of the cervix: A sexually transmitted infection? Lancet 1974, 1(7865):1037-1040

15. Sasieni P, Adams J: Effect of screening on cervical cancer mortality in England and Wales: Analysis of trends with an age period cohort model. BMJ 1999, 318(7193):1244-1245

16. Miller AB: Conundrums in screening for cancer. Int I Cancer 2010 126(5):1039-1046.

17. Bray F, Loos AH, McCarron P, Weiderpass E, Arbyn M, Moller H, et al: Trends in cervical squamous cell carcinoma incidence in 13 european countries: Changing risk and the effects of screening. Cancer Epidemiol Biomarkers Prev 2005, 14(3):677-686.

18. Statistics Canada CANSIM: Demographic estimates compendium 2010 Ottawa, Ontario: Ottawa Minister of Industry; 2010. September 29, 2010. Report No.: Table 051-0001.

19. On L, Semenciw RM, Mao Y: Orius software: Calculation of rates and epidemiologic indicators, and preparation of graphical output. Chronic Dis Can 2000, 21(3):134-136.

20. Band PR, Gaudette L, Hill GB, et al: The making of the Canadian cancer registry: Cancer incidence in Canada and its regions. 1969-88. Ottawa Ontario: Canadian Council of Cancer Registries; 1993.
21. Parkin DM, Chen WW, Ferlay J, et al: Comparability and quality control in cancer registration. IARC, Lyon: IARC Technical report No. 19; 1994.

22. International classification of diseases for oncology. Geneva, Switzerland: World Health Organization; 2000

23. World Heath Organization (WHO). ICD-10: International statistical classification of diseases and related health problems. Geneva: WHO; 1992:1.

24. Statistics Canada Vital Statistics: Mortality by causes of death. Ottawa, Canada: Canada Dominion Bureau of Statistics; 1932.

25. Statistics Canada Vital Statistics: Mortality by causes of death. Ottawa, Canada: Canada Dominion Bureau of Statistics; 1933.

26. Statistics Canada Vital Statistics: Mortality by causes of death. Ottawa, Canada: Canada Dominion Bureau of Statistics; 1934.

27. Statistics Canada Vital Statistics: Mortality by causes of death. Ottawa, Canada: Canada Dominion Bureau of Statistics; 1935.

28. Statistics Canada Vital Statistics: Mortality by causes of death. Ottawa, Canada: Canada Dominion Bureau of Statistics; 1936.

29. Statistics Canada Vital Statistics: Mortality by causes of death. Ottawa, Canada: Canada Dominion Bureau of Statistics; 1937.

30. Statistics Canada Vital Statistics: Mortality by causes of death. Ottawa, Canada: Canada Dominion Bureau of Statistics; 1938.

31. Statistics Canada Vital Statistics: Mortality by causes of death. Ottawa, Canada: Canada Dominion Bureau of Statistics; 1939.

32. Statistics Canada Vital Statistics: Mortality by causes of death. Ottawa, Canada: Canada Dominion Bureau of Statistics; 1940.

33. Statistics Canada Vital Statistics: Mortality by causes of death. Ottawa, Canada: Canada Dominion Bureau of Statistics; 1941.

34. Statistics Canada Vital Statistics: Mortality by causes of death. Ottawa, Canada: Canada Dominion Bureau of Statistics; 1942.

35. Statistics Canada Vital Statistics: Mortality by causes of death. Ottawa, Canada: Canada Dominion Bureau of Statistics: 1943.

36. Statistics Canada Vital Statistics: Mortality by causes of death. Ottawa, Canada: Canada Dominion Bureau of Statistics: 1944.

37. Statistics Canada Vital Statistics: Mortality by causes of death. Ottawa, Canada: Canada Dominion Bureau of Statistics: 1945.

38. Statistics Canada Vital Statistics: Mortality by causes of death. Ottawa Canada: Canada Dominion Bureau of Statistics; 1946.

39. Statistics Canada Vital Statistics: Mortality by causes of death. Ottawa, Canada: Canada Dominion Bureau of Statistics: 1947.

40. Statistics Canada Vital Statistics: Mortality by causes of death. Ottawa, Canada: Canada Dominion Bureau of Statistics; 1948.

41. Statistics Canada Vital Statistics: Mortality by causes of death. Ottawa, Canada: Canada Dominion Bureau of Statistics; 1949.

42. Statistics Canada: Population estimates 1950-1970. Ottawa, Ontario: Statistics Canada Demography Division; 1950-1970.

43. Zdeb MS: The probability of developing cancer. Am J Epidemio/ 1977 106:6-16.

44. Seidman H, Mushinski MH, Gelb SK, Silverberg E: Probabilities of eventually developing or dying of cancer-United States, 1985. CA Cancer J Clin 1985, 35(1):36-56.

45. Ponten J, Adami HO, Bergstrom R, Dillner J, Friberg LG, Gustafsson L, et al: Strategies for global control of cervical cancer. Int J Cancer 1995, 60(1):1-26

46. Green J, Kirwan J, Tierney J, Vale C, Symonds P, Fresco L, et al: Concomitant chemotherapy and radiation therapy for cancer of the uterine cervix. Cochrane Database Syst Rev 2005, 20:(3)(3):CD002225.

47. Monitoring Program Performance Working Group and the Monitoring Program Performance Data Group: Cervical Cancer Screening in Canada: Monitoring Program Performance 2006 -2008. Toronto: Pan-Canadian Cervical Screening Initiative, Canadian Partnership Against Cancer; 2011.

48. Lofters AK, Hwang SW, Moineddin R, Glazier RH: Cervical cancer screening among urban immigrants by region of origin: A population-based cohort study. Prev Med 2011, 51(6):509-16.

49. Johnston GM, Boyd CJ, Maclsaac MA: Community-based cultural predictors of pap smear screening in Nova Scotia. Can J Public Health 2004, 95(2):95-8.

50. Demers AA, Kliewer EV, Remes O, Onysko J, Dinner K, Wong T, Jayaraman GC: Cervical cancer among Aboriginal women in Canada. CMAJ 2012, 184:743-744.

51. van Wijngaarden WJ, Duncan ID, Hussain KA: Screening for cervical neoplasia in Dundee and Angus: 10 years on. Br J Obstet Gynecol 1995, 102(2):137-42. 
52. Popadiuk C, Stankiewic A, Dickinson J, Pogany L, Miller AB, Onysko J: Invasive Cervical Cancer Incidence and Mortality Among Canadian WomenAged 15 to 29 and the Impact of Screening. J Obstet Gynaecol Can 2012, 34(12):1167-1176.

53. Miller $A B$ : The (in)efficiency of cervical screening in Europe. Eur J Cancer 2002, 38(3):321-6.

54. Sasieni P, Castanon A, Cuzick J: Effectiveness of cervical screening with age: Population based case-control study of prospectively recorded data. BMJ 2009, 339:b2968.

55. Snider JA, Beauvais JE: Pap smear utilization in Canada: Estimates after adjusting the eligible population for hysterectomy status. Chronic Dis Can 1998, 19(1):19-24.

56. Miller AB, Visentin T, Howe GR: The effect of hysterectomies and screening on mortality from cancer of the uterus in Canada. Int J Cancer 1981, 27(5):651-7.

doi:10.1186/1471-2458-12-992

Cite this article as: Dickinson et al:: Reduced cervical cancer incidence and mortality in Canada: national data from 1932 to 2006. BMC Public Health 2012 12:992.

\section{Submit your next manuscript to BioMed Central and take full advantage of:}

- Convenient online submission

- Thorough peer review

- No space constraints or color figure charges

- Immediate publication on acceptance

- Inclusion in PubMed, CAS, Scopus and Google Scholar

- Research which is freely available for redistribution 